\title{
Cost and cost-effectiveness of cardiac surgery in elderly patients
}

\author{
Sandro Gelsomino, MD, PhD, ${ }^{\mathrm{a}, \mathrm{b}, \mathrm{c}}$ Roberto Lorusso, MD, PhD, ${ }^{\mathrm{b}}$ Ugolino Livi, $\mathrm{MD},{ }^{\mathrm{c}}$ \\ Gianluca Masullo, MD, ${ }^{\mathrm{b}}$ Fabiana Lucà, MD, ${ }^{\mathrm{a}}$ Jos Maessen, MD, PhD, ${ }^{\mathrm{d}}$ and Gian Franco Gensini, MD ${ }^{\mathrm{a}}$
}

Objective: Cost-effectiveness of heart surgery for elderly patients is still poorly defined. We evaluated outcome, quality of life (QoL), cost, and cost-effectiveness of octogenarians undergoing cardiac surgery.

\begin{abstract}
Methods: One thousand six hundred forty octogenarians undergoing various cardiac surgical procedures were prospectively studied between January 1998 and January 2009 and compared with similar patients aged 70 to 79 years. Several questionnaires were used to assess QoL. Six hundred age- and sex-matched healthy octogenarians and three hundred forty patients older than 80 years with medically treated valvular or coronary artery disease were healthy and unoperated control groups, respectively. In-hospital costs were obtained from the hospital's financial accounting department and cost-effectiveness was estimated and expressed as cost/QoL-adjusted life year (QALY) and cost-effectiveness ratio.
\end{abstract}

Results: Significant improvements occurred in elderly patients in Role Physical $(P<.001)$, Bodily Pain $(P<.001)$, General Health $(P=.004)$, Social Functioning $(P<.001)$, and Role Emotional $(P<.001)$, whereas Physical Functioning, Vitality, and Mental Health did not change (difference not signficant). Total direct costs were \$5293 higher in the octogenarian group. Cost-effectiveness was \$1391/QALY for elderly surgical patients, $\$ 516 /$ QALY for younger cardiac surgical patients $(P<.001$ vs elderly), \$897/QALY for untreated control group, and \$641/QALY for healthy control group $(P<.001$ vs elderly surgical patients). The cost-effectiveness ratio for octogenarians was $\$ 94,426$.

Conclusions: Our findings confirm that cardiac surgery in elderly patients remains controversial from a costeffectiveness standpoint, making econometric analysis an important component for any future evaluation of novel cardiovascular therapies. Our findings need to be confirmed by additional multicenter studies. (J Thorac Cardiovasc Surg 2011;142:1062-73)

Population aging is a shift in the distribution of a country's population toward greater ages in the developed countries. ${ }^{1}$ The sources of population aging lie in 2 possibly related demographic phenomena: rising life expectancy, largely as a result of the improvements in medical care being offered to the elderly population, and declining fertility, with the latter being the dominant contributor to population aging in the world today. ${ }^{2}$

It has been estimated that the world population will include more than 400 million persons at least 80 years old by the year $2050 .{ }^{1}$ This phenomenon is more noticeable in Italy, which has one of the oldest populations on the planet and which will include more than 7.2 million persons older than 80 years by the year $2050(13.3 \%$ vs $9.6 \%$ for the

From the Cardiac Surgery Unit, ${ }^{\mathrm{a}}$ Careggi Hospital, Florence, Italy; the Civic Hospital, ${ }^{\mathrm{b}}$ Brescia, Italy; the Department of Cardiovascular Sciences, ${ }^{\mathrm{c}}$ General Hospital S. Maria della Misericordia, Udine, Italy; and the Department of Cardiac Surgery, ${ }^{\mathrm{d}}$ Academic Hospital, Maastricht, The Netherlands.

Disclosures: Authors have nothing to disclose with regard to commercial support.

Received for publication April 12, 2010; revisions received Jan 7, 2011; accepted for publication Feb 9, 2011; available ahead of print April 14, 2011.

Address for reprints: Sandro Gelsomino, MD, PhD, Experimental Surgery Unit, Department of Heart and Vessels, Careggi Hospital, Viale Morgagni 85, 50134,

Florence, Italy (E-mail: sandro.gelsomino@libero.it).

0022-5223/\$36.00

Copyright (c) 2011 by The American Association for Thoracic Surgery doi:10.1016/j.jtcvs.2011.02.013 whole of Europe, $7.6 \%$ for the United States, $7.8 \%$ for North America, 5.2\% for Latin America and the Caribbean, $4.5 \%$ for Asia, $1.1 \%$ for Africa, and $6.8 \%$ for Australia and New Zealand). ${ }^{2}$

Because more than $40 \%$ of elderly persons have symptomatic cardiac disease, ${ }^{3}$ an increasing number of these patients may become candidates for cardiac surgery. Moreover, continuous advances in operative technique, myocardial protection, and perioperative care have led to a worldwide increase in cardiac surgery procedures for this age group. ${ }^{4}$ Nonetheless, controversy exists as to whether the considerable proportion of health care resources spent on the growing minority of elderly patients represents a cost-effective approach. To answer this question, we evaluated results, quality of life, costs, and resource use associated with cardiac surgery in octogenarians.

\section{MATERIALS AND METHODS Patients}

One thousand six hundred forty consecutive patients at least 80 years old undergoing cardiac surgery at 3 Italian institutions (Careggi Hospital, Florence, Civic Hospital, Brescia, and S. Maria Misericordia Hospital, Udine) between January 1998 and January 2009 were enrolled in the study. One thousand two hundred thirty consecutive patients aged 70 to 79 years undergoing cardiac operations during the same period were used as a comparison group for early and late outcomes, costs, and quality of life to test 


$$
\begin{aligned}
& \text { Abbreviations and Acronyms } \\
& \begin{aligned}
\text { CABG } & =\text { coronary artery bypass grafting } \\
\text { CER } & =\text { cost-effectiveness ratio } \\
\text { HC } & =\text { healthy control [group] } \\
\text { ICU } & =\text { intensive care unit } \\
\text { MCS } & =\text { mental composite score [of SF-36] } \\
\text { NYHA } & =\text { New York Heart Association } \\
\text { PCS } & =\text { physical composite score [of SF-36] } \\
\text { QALY } & =\text { quality-adjusted life years } \\
\text { SDS } & =\text { Zung's Self-Rating Depression Scale } \\
\text { SF-36 } & =\text { Medical Outcomes Short Form 36-Item } \\
& \text { Health Survey } \\
\text { UC } & =\text { unoperated control [group] }
\end{aligned}
\end{aligned}
$$

the hypothesis that cardiac surgery in octogenarians would prove to be as good and cost-effective as in septuagenarians. No exclusion or inclusion criteria were applied.

Costs and quality of life for patients at least 80 years old undergoing heart operations were further compared with those of 340 control octogenarians with unoperated heart disease (UC group). These were patients with valvular or coronary artery disease who were comparable to the study group in terms of clinical characteristics, severity of illness, and disability and who had the indication for the intervention given by a cardiac surgeon but were medically treated rather than undergoing surgery. Most of these patients refused the intervention $(85 \%)$ or had a "technical" contraindication to surgery ( $15 \%$, eg, porcelain aorta). The same analysis and cost assessment were applied and compared with results of actual surgical candidates. For this reason, there were no missing calculations in this data analysis. To explore whether the cost-effectiveness of cardiac surgery in elderly patients compares favorably with the social cost of the general elderly population, costs and quality of life of octogenarians undergoing heart operations were compared with those of 600 age-matched healthy (absence of neoplasm, chronic disease, cardiac disease) control subjects (HC group), and costs and quality of life of septuagenarians undergoing heart operations were similarly compared with those of an age-matched HC group $(n=486)$. Subjects in the HC groups were enrolled by 3 general practitioners linked to our clinical practice during the same period as the study. No formal exclusion criteria were applied.

Patients were enrolled and followed up by S.G., who was staff surgeon in these 3 institutions during the study period. Median follow-up was 69.8 months (interquartile range, 30.8-107.9 months).

In all cases, extubation was rigorously controlled per protocol. Age did not bias the protocol, and the decision to extubate was made independently of the surgeon and in a committed "early extubation" program. Furthermore, all transfusions were given only per protocol, not by bedside judgment.

The age of the patient was never a factor in the use of blood products. All patients with hemoglobin below $10 \mathrm{~g} / \mathrm{dL}$ underwent blood transfusion, and no difference was detected between octogenarians and septuagenarians with regard to the number of patients undergoing transfusion, because most patients who were anemic in the preoperative period had values between 10 and $13 \mathrm{~g} / \mathrm{dL}$. In accordance with the World Medical Association guidelines concerning ethical principles for medical research involving human subjects, the study was approved by the institutional ethics boards, and surgical candidates gave informed consent. Potential candidates who declined surgery and other control subjects gave informed consent to be included in the study. We had full access to the data and take responsibility for its integrity. All of us have read and agree to the article as written.

\section{Quality of Life Assessment}

Patients undergoing surgery were administered quality of life questionnaires preoperatively and at any follow-up appointments, along with clinical examination and echocardiographic control. Among survivors, seventy-six patients $(4.3 \%)$ were not able to participate in the follow-up questionnaires. Reasons for nonparticipation included Alzheimer disease $(\mathrm{n}=10)$, other neurologic problems $(\mathrm{n}=11)$, refusal $(\mathrm{n}=18)$, language barriers $(n=7)$, data entry problems $(n=3)$, terminal cancer $(n=12)$, and others $(\mathrm{n}=15)$.

Patients in the UC group were routinely administered quality of life questionnaires after admission and then followed up on a regular basis by cardiologists and cardiac surgeons, undergoing quality of life assessment at a median of 9 months (range, 4-13 months) from first admission to the surgery waiting list. Subjects in the HC group were followed up by the general practitioners who enrolled them in the study. For these subjects, quality of life questionnaires were administered at randomly chosen times at general practitioner clinics or by phone. All interviews were carried out by 2 surgeons (G.M., F.L.), both of whom were blinded to the aims of the study. The median time spent on interview was 28 minutes (interquartile range, 20-37 minutes).

Quality of life was measured with the Medical Outcomes Short Form 36-Item Health Survey (SF-36), ${ }^{5}$ which consists of 36 questions grouped into the following 8 multi-item domains (Appendix Table 1).: Physical Functioning, Role Physical, Bodily Pain, General Health, Vitality, Social Functioning, Role Emotional, and Mental Health. Furthermore, SF-36 also assesses 2 major health concepts, physical and mental, with 2 composite scores, the physical composite score (PCS) and the mental composite score (MCS). The physical scales (Physical Functioning, Role Physical, Bodily Pain, and General Health) make up the PCS, and the remaining 4 scales (Mental Health, Role Emotional, Vitality, and Social Functioning) make up the MCS. Reliability by the test-retest ${ }^{6}$ between baseline and at follow-up was good, with interclass correlation coefficients ranging between 0.73 and 0.86 . Internal consistency ${ }^{6}$ was good for the 8 scales, with Cronbach coefficients ranging between 0.85 and 0.95 .

The Seattle Angina Questionnaire was only applied to those patients with coronary artery disease necessitating isolated coronary artery bypass grafting $(\mathrm{CABG}){ }^{7}$ It represents a reliable and validated instrument that measures 5 clinical dimensions of health in patients with coronary artery disease (physical limitation, anginal stability, anginal frequency, treatment satisfaction, and disease perception).

Zung's Self-Rating Depression Scale (SDS) ${ }^{8}$ was used to assess depression. The questionnaire consists of 20 questions, 10 symptomatically positive and 10 symptomatically negative. Results were expressed as SDS raw score (sum of points for all 20 questions), SDS average score, and SDS index.

The Italian version of the Spielberger State-Trait Anxiety Inventory form $\mathrm{X}_{1}$ was used to measure state anxiety (how one feels at a particular moment), whereas form $X_{2}$ was used to assess trait anxiety (how one usually feels). ${ }^{9}$ The scores range from 20 (very low anxiety) to 80 (very high anxiety).

\section{Costs}

In-hospital costs were obtained from the hospitals' financial accounting departments. All billed items and their associated costs were assigned to 1 of the following 15 categories: preoperative (all costs before surgery), anesthesia (costs of anesthetics, equipment, and disposables used by anesthesiologists), operative (costs related to the use of the operating rooms and all surgical equipment and disposables used by surgeons), perfusion (costs of cardiopulmonary bypass equipment, cardioplegia, and disposables used by perfusionists), intensive care unit (ICU, costs of nursing, equipment, and room in the cardiovascular ICU), postoperative room (costs related to nursing, equipment, and room in the step-down unit), respiratory therapy (costs related to respiratory equipment, treatments, and therapist time), laboratory (costs of blood tests), blood bank (costs related to blood typing and 
transfusion), cardiologic laboratory (cost of electrocardiograms, echocardiograms, and other noninvasive vascular studies), radiology (costs of radiographs, computed tomographic scans, and magnetic resonance scans), pharmacy (costs of drugs and dispensing), therapies (costs of physical, occupational, and speech therapy), supplies, and other costs.

Postoperative costs were assigned to the following categories: physician visits, echocardiograms, anticoagulation therapy, rehospitalization, reoperation, complications, pharmacy, specialties, home care facilities, and other. We first calculated costs in the entire cardiac surgical population. Then operations were broken down into 6 categories: CABG, offpump CABG, aortic valve replacement, mitral valve replacement, mitral valve repair, aortic surgery (including surgery of the ascending aorta or aortic arch, with or without a prosthetic valve), and associated CABG and valve surgery.

Costs in $\mathrm{HC}$ and UC groups were divided into the following categories: home and skilled nursing facilities, general medicine, pharmacy, hospitalization, specialties, therapies, diagnostics, and other. These costs were obtained directly from institutions' cost-accounting systems or from Health Ministry rates for services.

Prices were originally calculated in euros, converted to 2009 value with yearly inflation factors ${ }^{10}$ obtained from the consumer price index, and then changed to US dollars ( $€ 1=\$ 1.4406$ US, currency rate as of January 1, 2010).

\section{Cost-effectiveness}

To calculate cost-effectiveness, the sum of lifetime costs was divided by the total quality-adjusted life years (QALYs) ${ }^{11}$ gained. The result was then divided by the number of patients.

The lifetime total costs in the operative groups were obtained by summing (1) in-hospital costs, (2) postoperative costs, and (3) for subjects who are currently alive, estimated lifetime costs.

Estimated survival after cardiac surgery was determined from the observed data from our follow-up system and completion of the currently censored lifetimes with a Gompertz regression model derived from the observed patient data. ${ }^{11}$ The simulation was repeated 1000 times, and the mean was used in the final calculation. ${ }^{11}$

Estimated lifetime costs were assigned to the following categories: physician visits, echocardiograms, anticoagulation therapy, re-hospitalization, re-operation, complications, pharmacy, specialties, home care facilities, and other. Data reflect resource acquisition costs, allocation of institutional cost, and indirect institutional costs derived from data obtained from Regional Health Care Administration Offices (Friuli Venezia Giulia, Toscana, Lombardia) or obtained from the service rates from the Italian Ministry of Health. To project the cost during these simulated future life years, physician visits and echocardiograms were assumed to occur annually. ${ }^{11,12}$ Hospitalization, rehospitalization, and reoperation were obtained by applying the hazard function to observed data. Complications not related to time were assumed to occur at the same constant rates during the observed patient-years.

QALYs were calculated on the basis of raw PCS and MCS. For both scores, each year in perfect health was assigned the value from 1 (maximum score 100) down to the value of 0.0 (minimum score 0 ), and values were added. For future simulated life years, PCS and MCS scores were linearly interpolated between the latest available raw scores and 0 (assumed for the end of life).

The life years of patients with unoperated heart disease or of healthy octogenarians were estimated from data obtained from the Italian National Institute of Statistics and from the Italian Superior Institute of Health concerning the natural history of unoperated surgical heart diseases, and a survival curve was built for each group. An average curve was then computed, weighted by sample size, and the area under this curve was the mean survival time. Each patient was randomly assigned a lifetime by sampling the survival time on the survival curves according to the probability of survival. ${ }^{11}$
Estimated lifetime costs were assigned to same subcategories used for operative patients. To project the cost during these simulated future life years, rates of physician visits, echocardiograms, hospitalization, and so on were obtained by the hazard function from data obtained from the Italian Superior Institute of Health and the Italian Ministry of Health.

QALYs were calculated as described. Similarly, for future simulated life years, PCS and MCS scores were linearly interpolated between the latest available raw scores and 0 (assumed for the end of life).

To allow a comparison with published reports, we also calculated a costeffectiveness ratio (CER), as suggested by Wu and coworkers. ${ }^{11}$ Briefly, the CER was the difference between the lifetime cost of operative patients and the lifetime cost of UC group patients (set at 0 ) divided by the difference in quality of life experienced by operative and UC groups. The QUALYs were estimated by mapping quality of life scores versus New York Heart Association (NYHA) functional class. Life years spent in NYHA functional classes I, II, III, and IV were estimated to be equivalent to $0.85,0.71$, 0.57 , and 0.43 QALYs, respectively. On the basis of generally accepted thresholds, a treatment with a CER less than $\$ 20,000$ is considered highly cost-effective, a treatment with a CER between $\$ 20,000$ and $\$ 100,000$ is acceptable but gradually less cost-effective, and a treatment with a CER more than $\$ 100,000$ is not cost-effective. ${ }^{11}$

\section{Statistical Analysis}

Variables were tested for their normal (Gaussian) distribution with the Kolmogorov-Smirnov test. Continuous data were expressed as mean \pm $\mathrm{SD}$, nonparametric data were presented as median and interquartile range, and frequencies were expressed as proportions. Categoric variables were compared with $\chi^{2}$ or Fisher's Exact test. We used Student $t$ tests (unpaired) to compare continuous variables, except when data were skewed, in which case the Mann-Whitney and the Wilcoxon tests were used for paired and unpaired comparisons, respectively, whereas the Kruskal-Wallis and the Friedman tests were used for matched and nonmatched multiple comparisons. The Dunn nonparametric post hoc test was then used to compare each pair of variables. No type I error adjustment was made for multiple testing.

Freedoms from death, cardiac events, and rehospitalization were estimated by use of the Kaplan-Meier method. Log-rank was used to detect differences between curves.

A multivariable Cox model was used to select independent predictors of death after the assessment of the proportional hazard assumption. The ln $(-1 n)$ survivor curves were assessed for categoric variables and quartiles of continuous variables. When curves were not roughly parallel, further evaluation was performed by including an interaction term of the covariate with time, which was evaluated for significance $(P<.05)$ and for whether inclusion resulted in a change of at least $20 \%$ in the hazard ratio for the main effect. When these criteria were used, no significant departure from the proportional hazard assumption was found. Models were validated with bootstrapping technique (1000 iterations).

The Cox model was fitted to compute the hazard ratio for death after adjustment for potential confounders (hypertension, smoking, diabetes, obesity, hypercholesterolemia, chronic renal disease, chronic obstructive pulmonary disease, cerebrovascular disease, NYHA class, EuroSCORE, pulmonary hypertension, endocarditis, previous percutaneous transluminal angioplasty, emergency-associated procedures, isolated CABG, multiple valve procedures, aortic crossclamp time, and cardiopulmonary bypass time). Backward stepwise selection was used, with a $P$ value to remove of 2 .

Because of the skewness of the cost data, generalized linear regression models ${ }^{13}$ were used that allow for nonnormal distributions. Our models used a $\gamma$ error distribution, and the link function was logistic. Thus the estimated regression coefficients are on the log scale, and their direction and magnitude provide an indication of their effect: positive (negative) values indicate increased (decreased) costs, with the cost multiplier being approximately the exponent of the regression coefficient. With regard to the cost modeling, however, because of the presence of cost values that 
were censored (eg, because some patients left the hospital and went to other medical settings from which costs could be not be accurately obtained), in some cases the censoring needed to be handled in the modeling. To examine the effect of censoring on in-hospital cost, we used the method of Zhao and colleagues, ${ }^{14}$ which weights observations by the inverse probability of being censored and integrates across patients' cost histories to correct for censoring. This analysis revealed a negligible bias resulting from censoring ( $\$ 82)$, which also did not vary by age group (operative octogenarian group vs operative septuagenarian group, $P=.87$ ).

SPSS version 12.0 (SPSS, Inc, an IBM Company, Chicago, Ill) and Stats Direct version 2.5.7 (StatsDirect, Sale, UK) software packages were used for calculations.

\section{RESULTS}

\section{Patient Characteristics}

Clinical characteristics presented in Table 1 show significant differences between octogenarians and septuagenarians with regard to gender $(P<.001)$, anemia $(P<.001)$, chronic obstructive pulmonary disease $(P=.005)$, cerebrovascular disease $(P=.002)$, and primitive neoplasm $(P=.04)$, which occurred more in older patients. In contrast, octogenarians were less likely to have diabetes $(P=.04)$ and hypercholesterolemia $(P<.001)$. With respect to operative procedures, the younger population had more CABG $(P=.04)$ and on-pump CABG $(P=.03)$ procedures, whereas octogenarians received a larger number of bioprosthetic valves $(P=.003)$.

\section{Early and Late Outcomes}

Outcome data are displayed in Table 2. Surgery in older patients was associated with higher incidences of postoperative atrial fibrillation $(P=.005)$ and agitation or disorientation $(P=.004)$, a longer intubation time $(P=.004)$, a greater need for blood transfusions $(P<.001)$, and a longer hospital stay $(P<.001)$. Furthermore, octogenarians showed a significantly higher in-hospital and 30-day mortality $(P<.001)$, with a lower percentage of patients discharged to home $(P<.001)$. Survival, freedom from cardiac events, and freedom from rehospitalization at 1,3 , 5 , and 8 years were significantly lower in octogenarians $(P<.001)$. At follow-up, NYHA functional class was significantly higher in octogenarians (median, 2; interquartile range, $2-3$; vs median, 1 ; interquartile range, $1-2$; $P=.004)$. Predictors of death are shown in Table 3 .

\section{Quality of Life}

Results of quality of life assessment are shown in Table 4. Quality of life of octogenarians undergoing heart operations was compared with age-matched UC and HC groups. To make a comparison with the younger population, quality of life of elderly patients (octogenarians) was compared with that of septuagenarians, either operative or $\mathrm{HC}$ group. Younger patients showed a significant improvement in quality of life across all SF-36 domains $(P<.001)$. Contrastingly, in the elderly group, significant improvements occurred in Role Physical $(P<.001)$, Bodily Pain $(P<.001)$, General Health $(P=.004)$, Social Functioning $(P<.001)$, and Role Emotional $(P<.001)$, whereas Physical Functioning, Vitality, and Mental Health did not change (difference not significant). Relative to the UC group, postoperative scores were higher in operative group octogenenarians, exclusive of Physical Functioning, Vitality, and Mental Health (difference not significant). Furthermore, the elderly operative group had higher scores for Bodily Pain $(P=.03)$, Social Functioning $(P=.02)$, and Role Emotional $(P=.002)$ in comparison with the HC group but showed lower scores in the Mental Health domain $(P=.003)$. All scores were significantly higher in younger patients than in elderly patients $(P<.001)$.

The entire cohort showed an improvement in Seattle Angina Questionnaire responses in all areas in the postoperative period. Nonetheless, postoperative scores were significantly higher in younger patients $(P<.001)$.

Trait anxiety did not change in elderly patients (difference not significant), whereas state anxiety did improve $(P=.03)$. Nonetheless, postoperative values of the elderly operative group were comparable with those of both UC and HC groups. Contrastingly, both trait $(P<.001)$ and state $(P=.04)$ anxieties were reduced in younger patients after surgery $(P<.001$ vs elderly). Finally, depression significantly worsened after operation in octogenarians $(P<.001)$, whereas it improved in younger patients $(P=.02 ; P<.001$ vs elderly).

\section{Costs and Cost-Benefit}

Cost data by service area and multivariable predictors of in-hospital costs are shown in Tables 5 and 6. Total direct costs of octogenarians and septuagenarians undergoing cardiac surgery were compared. Cost was higher in the elderly cohort than in the younger cohort $(+\$ 5293$, $P<.001)$, with the largest increases in ICU $(P=.02)$, respiratory therapy $(P<.001)$, blood bank $(P<.001)$, and pharmacy $(P=.004)$.

Cost-effectiveness values of surgery for operative octogenarian and septuagenarian groups were compared with the social cost of the general elderly population and with the social and medical costs of octogenarians with cardiac disease who did not undergo surgery. Cost-effectiveness was $\$ 1391 /$ QALY in the operative elderly group, \$516/ QALY in younger cardiac surgical patients $(P<.001$ vs elderly), \$897/QALY in UC group, and \$641/QALY in HC group $(P<.001$ vs. operated elderly). The CER for octogenarians was $\$ 94,426$.

\section{Costs and Cost-Benefit by Type of Intervention}

Cost data by type of intervention are shown in Table 7. Prices were consistently higher for octogenarians $(P<.001)$, with the largest differences in aortic surgery 
TABLE 1. Demographic and clinical characteristics

\begin{tabular}{|c|c|c|c|}
\hline & $\geq 80$ y $(n=1640)$ & $70-79$ y $(n=1230)$ & $P$ valu \\
\hline Age (y) & & & $<.001$ \\
\hline Range & $80-92$ & $70-79$ & \\
\hline Mean $\pm \mathrm{SD}$ & $83 \pm 2$ & $72 \pm 3$ & \\
\hline Female (No.) & $837(51 \%)$ & $382(31.1 \%)$ & $<.001$ \\
\hline Hypertension* (no.) & $967(58.9 \%)$ & $627(50.9 \%)$ & .08 \\
\hline Diabetes $\dagger$ (no.) & $393(23.9 \%)$ & $607(49.3 \%)$ & .004 \\
\hline Obesity $\ddagger$ (no.) & $49(2.9 \%)$ & $98(7.9 \%)$ & .054 \\
\hline Hypercholesterolemia $\S$ (no.) & $311(18.9 \%)$ & $467(37.9 \%)$ & $<.001$ \\
\hline Smoking (no.) & $393(23.9 \%)$ & $319(25.9 \%)$ & .6 \\
\hline $\begin{array}{l}\text { New York Heart Association functional class } \\
\text { (median and interquartile range) }\end{array}$ & $3[2-4]$ & $3[2-4]$ & $>.9$ \\
\hline $\begin{array}{l}\text { Canadian Cardiovascular Society angina class } \\
\text { (median and interquartile range) }\end{array}$ & $2[1-3]$ & $2[1-3]$ & .8 \\
\hline Anemia $\|($ no. $)$ & $89(5.4 \%)$ & $9(0.7 \%)$ & $<.001$ \\
\hline Renal failure (no.) & $279(17.0 \%)$ & $173(14.1 \%)$ & .08 \\
\hline Chronic obstructive pulmonary disease\# (no.) & $180(10.9 \%)$ & $57(4.6 \%)$ & .005 \\
\hline Peripheral vascular disease (no.) & $200(12.2 \%)$ & $110(8.9 \%)$ & .068 \\
\hline Cerebrovascular disease (no.) & $510(31.1 \%)$ & $221(17.9 \%)$ & .002 \\
\hline Myocardial infarction (no.) & $352(21.4 \%)$ & $282(22.9 \%)$ & .09 \\
\hline Primitive neoplasm (no.) & $93(5.6 \%)$ & $36(2.9 \%)$ & .04 \\
\hline Preoperative intra-aortic balloon pump (no.) & $65(3.9 \%)$ & $51(4.1 \%)$ & .9 \\
\hline Congestive heart failure (no.) & $459(27.9 \%)$ & $270(21.9 \%)$ & .054 \\
\hline Left main coronary disease (no.) & $229(13.9 \%)$ & $209(16.9 \%)$ & .08 \\
\hline Previous percutaneous transluminal angioplasty (no.) & $114(9.3 \%)$ & $87(7.7 \%)$ & .09 \\
\hline $\begin{array}{l}\text { Left ventricular ejection fraction } \\
\qquad(\%, \text { median and interquartile range })\end{array}$ & $46.5 \%[38.6 \%-49.9 \%]$ & $47.7 \%[37.0 \%-48.6 \%]$ & .79 \\
\hline Left ventricular ejection fraction $<0.35$ (no.) & $286(17.4 \%)$ & $221(17.9 \%)$ & .9 \\
\hline Pulmonary hypertension** (no.) & $78(4.7 \%)$ & $61(4.9 \%)$ & $>.9$ \\
\hline Endocarditis (no.) & $5(0.3 \%)$ & $14(1.1 \%)$ & $>.9$ \\
\hline \multicolumn{4}{|l|}{ EuroSCORE (median and interquartile range) } \\
\hline Additive & 9 [6-11] & $10[8-12]$ & .73 \\
\hline Logistic & $15[10-16]$ & $16[11-18]$ & .80 \\
\hline Status of surgery (no.) & & & .81 \\
\hline Elective & $673(41.0 \%)$ & $492(40.0 \%)$ & \\
\hline Urgent & $755(46.0 \%)$ & $591(47.9 \%)$ & \\
\hline Emergency & $212(13.0 \%)$ & $147(11.1 \%)$ & \\
\hline Redo procedure (no.) & $180(10.9 \%)$ & $144(11.7 \%)$ & .74 \\
\hline \multicolumn{4}{|l|}{ Surgical procedure data } \\
\hline Isolated CABG (no.) & $567(34.6 \%)$ & $606(49.3 \%)$ & .04 \\
\hline On cardiopulmonary bypass (on-pump, no.) & $238(42.0 \%)$ & $388(64.5 \%)$ & .03 \\
\hline Without cardiopulmonary bypass (off-pump, no.) & $329(58.0 \%)$ & $213(35.5 \%)$ & .03 \\
\hline Conversion off-pump to on-pump (no.) & $8(2.4 \%)$ & $6(2.8 \%)$ & .07 \\
\hline Grafts per patient (median and interquartile range) & $2[1-3]$ & $2[1-3]$ & $>.9$ \\
\hline Arterial grafts per patient (median and interquartile range) & $1[0-1]$ & $1[0-1]$ & $>.9$ \\
\hline Isolated valve (no.) & $382(23.3 \%)$ & $119(9.7 \%)$ & $<.001$ \\
\hline CABG with valve (no.) & $441(26.9 \%)$ & $284(23.1 \%)$ & .1 \\
\hline CABG with valve and other (no.) & $130(7.9 \%)$ & $109(8.9 \%)$ & .18 \\
\hline Valve with other (no.) & $113(6.9 \%)$ & $106(8.6 \%)$ & .07 \\
\hline Other (no.) & $7(0.4 \%)$ & $6(0.5 \%)$ & $>.9$ \\
\hline Biologic prosthesis (no.) & $1012(94.1 \%)$ & $490(77.8 \%)$ & .003 \\
\hline Mechanical prosthesis (no.) & $64(5.9 \%)$ & $140(22.2 \%)$ & .003 \\
\hline Associated carotid endarterectomy (no.) & $86(5.2 \%)$ & $50(4.0 \%)$ & .21 \\
\hline Other vascular operations (no.) & $45(2.7 \%)$ & $23(1.9 \%)$ & .08 \\
\hline
\end{tabular}


TABLE 1. Continued

\begin{tabular}{|c|c|c|c|}
\hline & $\geq 80$ y $(n=1640)$ & $70-79$ y $(n=1230)$ & $P$ value \\
\hline $\begin{array}{l}\text { Cardiopulmonary bypass time } \\
\text { (min, median and interquartile range) }\end{array}$ & $110[98-144]$ & 118 [100-157] & .8 \\
\hline $\begin{array}{l}\text { Aortic crossclamp time } \\
\text { (min, median and interquartile range) }\end{array}$ & 73 [35-120] & 75 [42-137] & .8 \\
\hline
\end{tabular}

$(+\$ 6100)$ and associated valve surgery and CABG $(+\$ 6016)$. The subanalysis of cost data by service area showed that the greatest increase in in-hospital costs for elderly patients were for those referred to the ICU $(+\$ 1221)$ and for respiratory therapy $(+\$ 1009)$. Pharmacy costs were higher for older patients in all types of interventions, whereas costs of blood typing and transfusion were significantly higher in more complex surgical procedures.

CER was significantly lower for septuagenarians independent of the type of intervention (Figure 1, A). The CER values for octogenarians were higher than $\$ 100,000$ for aortic surgery and associated CABG and valve surgery and above $\$ 20,000$ in all cases (Figure 1, B).

\section{DISCUSSION}

Nationwide in Italy, cardiac surgery is being performed more frequently in patients aged 80 years and older. Nonetheless, controversy exists as to whether the considerably high proportion of health-care resources expended on the growing minority of elderly patients represents a costeffective approach in an attempt to maintain a meaningful quality of life. $^{15,16}$

Our results confirm that cardiac procedures can be offered to octogenarians with acceptable morbidity and mortality, significant improvement in clinical status, and satisfactory long-term results, comparable with those reported in the literature. ${ }^{17-19}$

Because our older patient group had lower prevalences of diabetes and obesity (which may have been associated with earlier death), one might have assumed better outcomes for this group. In contrast, early mortality and complications were significantly higher in elderly patients, even after accounting for these risk factors.

Additionally, among older patients, an overall absolute improvement was shown in SF-36 scores, although this was lower than in younger patients. Specifically, improvements were noted in the domains of Role Physical, Bodily Pain, General Health, Social Functioning, and Role Emotional, as well as in the MCS and PCS metascores. There was little or no absolute improvement in Physical Functioning, Vitality, and Mental Health. Compared with the sex- and age-matched $\mathrm{HC}$ group, there were statistically significant improvements in Bodily Pain, Social Functioning, and Role Emotional domains, whereas Mental Health score was lower. Finally, postoperative values for the SF36 domain were higher than in the UC group, although in Physical Functioning, Vitality, and Mental Health, this difference did not reach statistical significance.

Furthermore, those elderly patients who underwent CABG were very satisfied with treatment and had stable and infrequent anginal symptoms. Finally, elderly patients showed a significant improvement in state anxiety, whereas trait anxiety did not change, and depression significantly worsened after operation. Thus our findings confirm an improved postoperative quality of life for octogenarians undergoing cardiac operations. ${ }^{16-21}$ Nonetheless, as the expenses of health care are constantly increasing, approaches to optimize costs in all departments of medicine have a high priority. Thus every clinical decision cannot set aside an accurate cost and cost-benefit analysis. For this reason, the number of articles published on cost-benefit analysis has increased enormously in recent years.

In our experience, total costs were $\$ 5293$ higher in the octogenarian group, in accordance with reported data from other investigators. ${ }^{4}$ This increase was attributable to higher costs of ICU, respiratory therapy, blood bank, and pharmacy. In addition, prolonged ICU stay, hospital stay, and intubation time were, with sternal infection, independent predictors of costs. Regardless, an age of at least 80 years was the strongest predictor of in-hospital costs in our model.

A subanalysis of costs by intervention showed that costs related to blood typing and transfusion were significantly higher for octogenarians only in more complex procedures, suggesting that adequate preoperative (eg, bone marrow stimulation with erythropoietin, controlled preoperative transfusion), intraoperative (ultra-filtration, prepriming of the extracorporeal circuit with the patient's own blood), and postoperative (recombinant activated factor VII) management for anemia and bleeding are mandatory to improve the outcome in elderly patients undergoing complex cardiac surgery. Furthermore, our data suggest that respiratory complications represent an important factor that significantly increases costs of surgery in the elderly population. Detailed 
TABLE 2. Early and late outcomes

\begin{tabular}{|c|c|c|c|}
\hline & $\geq 80$ y $(n=1640)$ & $70-79$ y $(n=1230)$ & $P$ value \\
\hline Significant bleeding, surgical reexploration* (no.) & $146(8.9 \%)$ & $109(8.8 \%)$ & .9 \\
\hline Sternal infection (no.) & $16(0.9 \%)$ & $17(1.3 \%)$ & .6. \\
\hline Low output syndrome $\dagger$ (no.) & $148(9.9 \%)$ & $84(6.9 \%)$ & .06 \\
\hline Perioperative myocardial infarction $\ddagger$ (no.) & $82(5.0 \%)$ & $62(5.0 \%)$ & $>.9$ \\
\hline Atrial fibrillation $\S$ (no.) & $845(51.5 \%)$ & $385(31.3 \%)$ & .005 \\
\hline Permanent pacemaker (no.) & $115(7.0 \%)$ & $62(5.0 \%)$ & .09 \\
\hline Postoperative intra-aortic balloon pump (no.) & $17(1.0 \%)$ & $14(1.1 \%)$ & .8 \\
\hline Pneumonia $\|$ (no.) & $98(5.9 \%)$ & $32(2.6 \%)$ & .06 \\
\hline \multicolumn{4}{|l|}{ Renal failure (no.) } \\
\hline Hemofiltration & $39(2.3 \%)$ & $37(3.0 \%)$ & .25 \\
\hline Hemodialysis & $50(3.0 \%)$ & $24(1.9 \%)$ & \\
\hline Hepatic insufficiency (no.) & $1(0.1 \%)$ & $2(0.1 \%)$ & .9 \\
\hline \multicolumn{4}{|l|}{ Neurologic dysfunction (no.) } \\
\hline Transient ischemic attack & $36(2.2 \%)$ & $20(1.6 \%)$ & .1 \\
\hline Stroke\# & $123(7.5 \%)$ & $59(4.8 \%)$ & .18 \\
\hline Agitation, disorientation & $118(7.2 \%)$ & $36(2.9 \%)$ & .004 \\
\hline Hemotransfusion (no.) & $1594(85.0 \%)$ & $689(56.9 \%)$ & $<.001$ \\
\hline Red blood cells (IU, median and interquartile range) & $5[3-8]$ & $2[1-3]$ & $<.001$ \\
\hline Platelets (IU, median and interquartile range) & $1[1-2]$ & $1[0-1]$ & .01 \\
\hline Plasma (IU, median and interquartile range) & $4[3-5]$ & $2[1-3]$ & $<.001$ \\
\hline Intensive care unit stay ( $\mathrm{d}$, median and interquartile range) & $5[3-8]$ & $1[1-3]$ & $<.001$ \\
\hline Intubation time ( $\mathrm{h}$, median and interquartile range) & $10[6-18]$ & $8[4-15]$ & .004 \\
\hline Intubation $>5 \mathrm{~d}$ (no.) & $131(7.9 \%)$ & $40(3.2 \%)$ & $<.001$ \\
\hline Reintubation (no.) & $148(9.1 \%)$ & $40(3.2 \%)$ & $<.001$ \\
\hline Hospital stay ( $d$, median and interquartile range) & $15[8-24]$ & $10[8-12]$ & $<.001$ \\
\hline In-hospital death (no.) & $121(7.4 \%)$ & $13(1.0 \%)$ & $<.001$ \\
\hline Discharged (no.) & $1,519(92.6 \%)$ & $1,217(99.0 \%)$ & \\
\hline Home (no.) & $531(35.1 \%)$ & $741(60.9 \%)$ & $<.001$ \\
\hline Rehabilitation hospital (no.) & $637(41.8 \%)$ & $408(33.5 \%)$ & .006 \\
\hline Other (no.) & $351(23.1 \%)$ & $68(5.6 \%)$ & $<.001$ \\
\hline Early death** (no.) & $135(8.2 \%)$ & $15(1.2 \%)$ & $<.001$ \\
\hline \multicolumn{4}{|l|}{ Freedom from late death $(\%)$} \\
\hline $1 \mathrm{y}$ [patients at risk] & $79 \% \pm 6 \%[1318]$ & $91 \% \pm 4 \%[989]$ & $<.001 \dagger \dagger$ \\
\hline 3 y [patients at risk] & $69 \% \pm 9 \%[836]$ & $86 \% \pm 8 \%[627]$ & $<.001 \dagger \dagger$ \\
\hline $5 \mathrm{y}$ [patients at risk] & $60 \% \pm 12 \%[508]$ & $78 \% \pm 11 \%[381]$ & $<.001 \dagger \dagger$ \\
\hline $8 \mathrm{y}$ [patients at risk] & $40 \% \pm 14 \%[246]$ & $65 \% \pm 14 \%[184]$ & $<.001 \dagger \dagger$ \\
\hline \multicolumn{4}{|l|}{ Freedom from cardiac events $(\%)$} \\
\hline $1 \mathrm{y}$ [patients at risk] & $80 \% \pm 8 \%[1136]$ & $100 \%[911]$ & $<.001 \dagger \dagger$ \\
\hline $3 \mathrm{y}$ [patients at risk] & $70 \% \pm 12 \%[815]$ & $94 \% \pm 2 \%[618]$ & $<.001 \dagger \dagger$ \\
\hline $5 \mathrm{y}$ [patients at risk] & $61 \% \pm 11 \%[476]$ & $86 \% \pm 6 \%[360]$ & $<.001 \dagger \dagger$ \\
\hline 8 y [patients at risk] & $53 \% \pm 11 \%[228]$ & $86 \% \pm 6 \%[174]$ & $<.001 \dagger \dagger$ \\
\hline \multicolumn{4}{|l|}{ Freedom from rehospitalization $(\%)$} \\
\hline $1 \mathrm{y}$ [patients at risk] & $82 \% \pm 7 \%[1295]$ & $98 \% \pm 1 \%[972]$ & $<.001 \dagger \dagger$ \\
\hline $3 \mathrm{y}$ [patients at risk] & $73 \% \pm 13 \%[820]$ & $89 \% \pm 8 \%[615]$ & $<.001 \dagger \dagger$ \\
\hline $5 \mathrm{y}$ [patients at risk] & $61 \% \pm 15 \%[492]$ & $84 \% \pm 8 \%[369]$ & $<.001 \dagger \dagger$ \\
\hline $8 \mathrm{y}$ [patients at risk] & $36 \% \pm 18 \%[230]$ & $79 \% \pm 14 \%[172]$ & $<.001 \dagger \dagger$ \\
\hline
\end{tabular}

Postoperative complications were noted using the criteria of the Society of Thoracic Surgeons. *Significant bleeding was compromised hemodynamics, bleeding of at least 500 $\mathrm{mL} / \mathrm{h}$ during the first postoperative hour, bleeding of at least $300 \mathrm{~mL} / \mathrm{h}$ for 3 consecutive hours after chest closure, or bleeding of at least $1200 \mathrm{~mL} / \mathrm{h}$ after the fifth postoperative

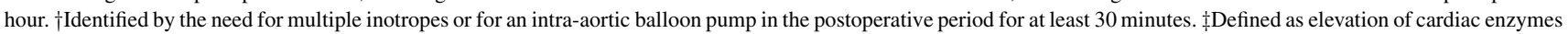
$(\geq 50 \mathrm{IU})$ in association with new $\mathrm{Q}$ waves or ST-T interval. §Atrial fibrillation was noted when it was sustained for at least 30 minutes or required treatment. \|Defined by clinical criteria, including chest roentgenographic findings and sputum culture results that mandated antibiotic therapy. $\uparrow$ Defined as a new, focal neurologic deficit lasting less than 24 hours. \#Defined as a new, focal neurologic deficit that persisted at discharge. **Defined as death occurring within 30 days of operation. $\dagger \dagger$ Significance by log-rank test.

clinical history, clinical examination, and evaluation of functional status remain the most important preoperative assessment instruments. Patients who smoke cigarettes should quit at least 8 weeks before surgery to minimize high airway reactivity and the risk of bronchospastic obstruction of the airway, mucus trapping, and regional atelectasis, and high-risk elderly patients should be trained in forced cough and lung expansion techniques before surgery if possible, 
TABLE 3. Multivariable predictors of death

\begin{tabular}{|c|c|c|c|}
\hline & $\begin{array}{c}\text { Adjusted } \\
\text { hazard ratio* }\end{array}$ & $\begin{array}{c}\text { Bias-corrected } \\
95 \% \text { confidence } \\
\text { interval }\end{array}$ & $\begin{array}{c}P \\
\text { value } \\
\end{array}$ \\
\hline $\begin{array}{l}\text { Perioperative myocardial } \\
\text { infarction }\end{array}$ & 2.9 & $1.7-4.0$ & $<.001$ \\
\hline Postoperative stroke & 2.7 & $1.9-3.9$ & $<.001$ \\
\hline Postoperative renal failure & 2.1 & $1.3-3.5$ & $<.001$ \\
\hline $\begin{array}{l}\text { Chronic obstructive } \\
\text { pulmonary disease }\end{array}$ & 1.9 & $1.5-2.5$ & $<.001$ \\
\hline $\begin{array}{l}\text { Preoperative congestive heart } \\
\text { failure }\end{array}$ & 1.6 & $1.3-2.0$ & $<.001$ \\
\hline Multiple valve procedure & 1.2 & $1.0-1.5$ & .004 \\
\hline $\begin{array}{l}\text { Urgent or emergency } \\
\text { procedure }\end{array}$ & 0.7 & $0.5-0.9$ & .01 \\
\hline Prolonged ventilation & 0.6 & $0.3-0.8$ & .04 \\
\hline \multicolumn{4}{|c|}{$\begin{array}{l}\text { *Validated by bootstrapping technique (1000 iterations). The model was fitted to } \\
\text { compute the hazard ratio for death after adjustment for potential confounders (hyper- } \\
\text { tension, smoking, diabetes, obesity, hypercholesterolemia, chronic renal disease, } \\
\text { chronic obstructive pulmonary disease, cerebrovascular disease, New York Heart As- } \\
\text { sociation functional class, EuroSCORE, pulmonary hypertension, endocarditis, pre- } \\
\text { vious percutaneous transluminal angioplasty, emergency associated procedures, } \\
\text { isolated coronary artery bypass grafting, multiple valve procedures, aortic crossclamp } \\
\text { time, cardiopulmonary bypass time). Backward stepwise selection was used, with a } P \\
\text { value to remove of } .2 \text {. }\end{array}$} \\
\hline
\end{tabular}

because there is some evidence that preoperative regular chest physiotherapy significantly decreases the incidence of pulmonary complications. ${ }^{22}$ Furthermore, the stay in the ICU was longer for elderly patients who underwent combined CABG and valve surgery or aortic surgery than for patients who underwent other types of cardiac surgery and for patients younger than 80 years.

In our experience, however, the most common event affecting the ICU stay is atrial fibrillation. With advancing age, fibrosis in the atria increases, a situation that leads to reentrant excitation and atrial fibrillation. ${ }^{22}$ The management of atrial fibrillation should be based on the severity of the signs and symptoms. In most instances, however, initial treatment focuses on controlling the rapid ventricular response. The choice of antiarrhythmic agent should be based on the presence or absence of structural heart disease and the tolerability, ease of administration, and side effects of the agent. ${ }^{22}$

The main finding of our study was that the CER of cardiac procedures in octogenarians was higher than that in septuagenarians (2.83-fold), as well as in UC (1.97-fold) and HC (2-fold) groups. In our experience, the CER was

TABLE 4. Quality of life assessment

\begin{tabular}{|c|c|c|c|c|c|c|c|}
\hline & \multicolumn{4}{|c|}{$\geq \mathbf{8 0} \mathbf{y}$} & \multicolumn{3}{|c|}{$70-79 y$} \\
\hline & $\mathrm{HC}$ & $\mathbf{U C}$ & Baseline & Postoperative & $\mathrm{HC}$ & Baseline & Postoperative \\
\hline \multicolumn{8}{|l|}{ SF-36 } \\
\hline Physical Functioning & $52[28-75]$ & $41[22-84]$ & $40[22-57]$ & $46[24-68]$ & $75[45-90]$ & $47[28-64]$ & $76[36-88]^{*}+\dagger$ \\
\hline Role Physical & $45[20-70]$ & 25 [13-44] & $12[0-35]$ & $45[25-55]^{*}+$ & 75 [30-100] & $31[29-66]$ & $75[35-90]^{*} \S$ \\
\hline Bodily Pain & $62[41-84]$ & 40 [22-57] & $36[19-48]$ & $70[39-97]^{*}+\S$ & 75 [41-100] & $32[33-74]$ & $72[60-100]^{*}$ \\
\hline General Health & 40 [22-59] & 35 [20-58] & $30[15-45]$ & $45[23-64]^{*} \ddagger$ & $55[34-73]$ & 48 [21-59] & $74[58-85]^{*,+}+\|$ \\
\hline Vitality & $44[28-59]$ & 38 [23-54] & $36[12-48]$ & $44[21-67]$ & $56[40-75]$ & 33 [19-59] & $58[35-72]^{*}, \S$ \\
\hline Social Functioning & 62 [38-89] & $47[32-64]$ & 50 [37-77] & $73[45-86]^{*}+\S$ & $75[50-100]$ & 53 [34-79] & $90[75-100]^{*}+\nmid \mid \|$ \\
\hline Role Emotional & 66 [20-87] & $46[22-74]$ & $41[12-62]$ & $75[67-92]^{*}+\nmid \S$ & $92[43-100]$ & $58[20-56]$ & $94[67-100]^{*} \nmid$ \\
\hline Mental Health & $52[34-75]$ & $41[28-70]$ & 36 [26-68] & $42[20-67] \S$ & 65 [45-82] & $56[33-72]$ & $74[60-80]^{*} \nmid$ \\
\hline Physical composite score & $50[28-72]$ & 35 [19-60] & $29[14-46]$ & $51[27-71]^{*} \ddagger$ & 70 [20-91] & 40 [28-65] & $74[48-93]^{*} \dagger$ \\
\hline Mental composite score & $56[34-71]$ & $43[26-65]$ & 40 [21-63] & $58[38-78]^{*} \ddagger$ & $71[44-90]$ & $41[26-66]$ & $82[60-94]^{*}+\dagger^{\prime} \|$ \\
\hline \multicolumn{8}{|l|}{ SAQ $(\mathrm{n}=987)$} \\
\hline Physical limitation & - & - & $42[33-50]$ & 77 [63-92]* & - & $44[33-55]$ & $83[63-100]^{*} \dagger$ \\
\hline Anginal stability & - & - & $32[21-48]$ & $67[55-80]^{*}$ & - & $35[24-51]$ & $94[83-100]^{*} \dagger$ \\
\hline Anginal frequency & - & - & $42[24-57]$ & 79 [67-91]* & - & 39 [26-53] & $92[79-100]^{*} \dagger$ \\
\hline Treatment satisfaction & - & - & $52[74-90]$ & $76[76-96]^{*}$ & - & 51 [73-89] & $88[77-100]^{*} \dagger$ \\
\hline Disease perception & - & - & 29 [23-35] & $76[68-82]^{*}$ & - & $34[28-40]$ & $93[82-100]^{*} \uparrow$ \\
\hline \multicolumn{8}{|l|}{ STAI } \\
\hline $\mathrm{X}_{1}$ & 35 [18-45] & 40 [25-57] & $42[30-50]$ & $35[28-43]^{*}$ & 25 [14-29] & 39 [28-45] & $25[19-36]^{*} \dagger$ \\
\hline $\mathrm{X}_{2}$ & $39[36-50]$ & $36[27-42]$ & $38[29-45]$ & $36[27-42]$ & $28[13-34]$ & 38 [28-45] & $30[20-42]^{*}+\dagger$ \\
\hline \multicolumn{8}{|l|}{ SDS } \\
\hline Raw score & $40[22-43]$ & 49 [30-64] & $48[32-55]$ & $58[26-67]^{*}+\S$ & $30[21-44]$ & $44[28-64]$ & $36[20-40]^{*} \uparrow$ \\
\hline Average score & $2.1[1.0-3.0]$ & $2.4[1.1-3.7]$ & $2.4[1.1-4.0]$ & $2.9[1.3-4.5]^{*}+\S$ & $1.4[0.8-1.6]$ & $2.2[1.2-3.5]$ & $1.8[0.9-2.0]^{*}+\dagger$ \\
\hline Index & $0.5[0.3-0.7]$ & $0.6[0.2-0.8]$ & $0.6[0.2-0.9]$ & $0.7[0.6-0.9]^{*}+\S$ & $0.3[0.1-0.5]$ & $0.5[0.3-0.6]$ & $0.4[0.3-0.5]^{*} \uparrow$ \\
\hline
\end{tabular}


TABLE 5. Cost data by service area

\begin{tabular}{|c|c|c|c|}
\hline & $\geq 80 \mathrm{y}$ & $70-79 y$ & $P$ value \\
\hline Preoperative & $\$ 914[\$ 390-\$ 1470]$ & $\$ 693[\$ 297-\$ 1560]$ & .4 \\
\hline Anesthesia & $\$ 1603$ [\$968-\$1944] & $\$ 1199$ [\$950-\$1586] & .07 \\
\hline Operative & $\$ 3783$ [\$1710-\$4887] & $\$ 3499[\$ 1680-\$ 4570]$ & .1 \\
\hline Perfusion & $\$ 2674[\$ 1500-\$ 3885]$ & $\$ 2180[\$ 1260-\$ 2650]$ & .06 \\
\hline Intensive care unit & $\$ 2853[\$ 1518-\$ 3980]$ & $\$ 1990[\$ 910-\$ 2720]$ & .006 \\
\hline Postoperative room & $\$ 1103$ [\$281-\$1230] & $\$ 840[\$ 210-\$ 996]$ & .3 \\
\hline Respiratory therapy & $\$ 1431$ [\$670-\$1695] & $\$ 575[\$ 58-\$ 201]$ & .006 \\
\hline Laboratory & $\$ 493[\$ 140-\$ 655]$ & $\$ 328[\$ 110-\$ 487]$ & .8 \\
\hline Blood bank & \$804 [\$310-\$1930] & $\$ 250[\$ 107-\$ 340]$ & .04 \\
\hline Cardiology laboratory & $\$ 162[\$ 90-\$ 231]$ & $\$ 186[\$ 100-\$ 210]$ & .9 \\
\hline Radiology & $\$ 196[\$ 55-\$ 281]$ & $\$ 101[\$ 47-\$ 225]$ & $>.9$ \\
\hline Pharmacy & $\$ 2087$ [\$1077-\$2599] & $\$ 1185$ [\$420-\$1313] & $<.001$ \\
\hline Therapies & $\$ 424[\$ 101-\$ 560]$ & $\$ 248[\$ 96-\$ 512]$ & .07 \\
\hline Supplies & $\$ 318[\$ 48-\$ 543]$ & $\$ 290[\$ 35-\$ 469]$ & $>.9$ \\
\hline Other & $\$ 197[\$ 38-\$ 355]$ & $\$ 185[\$ 30-\$ 341]$ & $>.9$ \\
\hline Total direct cost & $\$ 19,042[\$ 10,975-\$ 29,479]$ & $\$ 13,749[\$ 6464-\$ 18,856]$ & $<.001$ \\
\hline
\end{tabular}

Total direct costs of octogenarians and septuagenarians undergoing cardiac surgery were compared. Data are presented as median and interquartile range. Prices are in US dollars but were originally calculated in euros ( $€ 1=\$ 1.34829$ US as of May 29, 2007). Preoperative includes all costs from admission to surgery. Anesthesia includes cost of anesthetics, equipment, and disposables used by anesthesiologists. Operative includes costs of surgery, use of the operating room, surgical equipment, and disposables used by surgeons. Perfusion includes cost of cardiopulmonary bypass equipment, cardioplegia, and disposables used by the perfusionists. Intensive care unit includes cost of nursing, equipment, and room in the intensive care unit. Postoperative room includes cost of nursing, equipment, and room on the step-down unit. Respiratory therapy includes costs related to respiratory equipment. Laboratory includes cost of blood tests. Blood bank includes cost of blood typing and transfusion. Cardiology laboratory includes cost of electrocardiograms, echocardiograms, and noninvasive vascular studies. Radiology includes cost of radiologic examinations, computed tomographic scans, and magnetic resonance scans. Pharmacy includes cost of pharmacy drugs and service. Therapies includes cost of physical, occupational, and speech therapies.

very high $(\$ 94,426)$, and cardiac surgery proved not to be cost effective for elderly patients undergoing aortic surgery or associated CABG and valve procedures and barely costeffective for other cardiac surgery interventions. Our findings are in contrast with those of Wu and coworkers, ${ }^{11,23,24}$ who carried out a very precise economic analysis on 4617 patients undergoing aortic valve replacement and concluded that this procedure is very cost-effective, especially for elderly patients. Apart from differences with our patient population, which included all cardiac surgical interventions other than valve procedures, our dissimilar results might be due mainly to the different method used to estimate life years in our UC group.

Is cardiac surgery in octogenarians always reasonable? Cardiac surgeons, cardiologists, and general practitioners should consider that results must justify the investment and that quality of life, costs, and cost-benefit are valuable surgical end points. When an elderly patient is brought to our attention as "in good form, looking younger than his or her age," we should keep in mind the words of Thibault's discussant, who said, "There is nothing like cardiac surgery to bring out a patient's true age." ${ }^{25}$ There is abundant evidence that elderly patients properly selected and referred to cardiac surgery have improvements in their health, quality of life, and life expectancy, and that under these circumstances the treatment is worth its costs and resources used. On the other hand, although denying surgery to those elderly patients who have no chance of benefiting from operation might not be ethically incorrect, surgery "at any cost" not supported by any scientific evidence might well be morally wrong.

Certainly, decision making is often difficult, and weighing the risk-benefit of surgery may be a complex matter, particularly for elderly patients. Furthermore, currently available risk assessments are certainly suboptimal in this setting. A refinement of adopted patient selection criteria or factors influencing postoperative outcome should be addressed. Once these advances in patients selection and risk analysis have been achieved, a more ethical and appropriate costeffectiveness estimate of surgical treatment would be possible

TABLE 6. Multivariable predictors of in-hospital costs

\begin{tabular}{|c|c|c|c|c|c|}
\hline Variable & Coefficient & $95 \% \mathrm{CI}$ & SE & $\mathbf{X}^{2}$ & $P$ value \\
\hline Age $\geq 80 y$ & 0.7641 & $0.6162-0.9143$ & 0.0650 & 11.84 & $<.001$ \\
\hline Intensive care unit stay & 0.4012 & $0.2611-0.5413$ & 0.0813 & 5.60 & $<.001$ \\
\hline Hospital Stay & 0.3153 & $0.6402-0.4329$ & 0.0711 & 4.75 & $<.001$ \\
\hline Prolonged intubation & 0.2199 & $0.1309-0.3218$ & 0.0482 & 4.29 & $<.001$ \\
\hline Sternal infection & 0.0539 & $0.0111-0.0971$ & 0.0231 & 2.44 & .004 \\
\hline Intercept & 9.1098 & $8.9077-9.3013$ & 0.0990 & 92.36 & $<.001$ \\
\hline
\end{tabular}

Goodness of fit expressed by likelihood ratio $\chi^{2} 81.741, P<.001 . C$, Confidence interval. 
TABLE 7. Cost data by service area by surgical procedure

\begin{tabular}{|c|c|c|c|c|c|c|c|}
\hline & CABG & OPCAB & AVR & MV replacement & MV repair & Ao surgery & CABG + valve \\
\hline \multicolumn{8}{|l|}{ Preoperative } \\
\hline$\geq 80 \mathrm{y}$ & $\$ 897[\$ 402-\$ 1437]$ & $\$ 856[\$ 388-\$ 1412]$ & $\$ 922[\$ 418-\$ 1478]$ & $958[\$ 438-\$ 1514]$ & $885[\$ 411-\$ 1420]$ & $901[\$ 412-\$ 1487]$ & $944[\$ 444-\$ 1533]$ \\
\hline $70-79$ y & $\$ 669[\$ 307-\$ 1286]$ & $\$ 648[\$ 295-\$ 1244]$ & $\$ 731[\$ 311-\$ 1392]$ & $762[\$ 330-\$ 1417]$ & $680[\$ 299-\$ 1274]$ & $700[\$ 307-\$ 1361]$ & $738[\$ 322-\$ 1337]$ \\
\hline$P$ value & .41 & .42 & .09 & .10 & .42 & .10 & .25 \\
\hline \multicolumn{8}{|l|}{ Anesthesia } \\
\hline$\geq 80 \mathrm{y}$ & $\$ 1580[\$ 902-\$ 1640]$ & $\$ 1495[\$ 880-\$ 1590]$ & $\$ 1600[\$ 960-\$ 1980]$ & $1680[\$ 1058-\$ 2030]$ & 1593 [\$954-\$1875] & 1564 [\$930-\$1904] & $1650[\$ 1004-\$ 2044]$ \\
\hline $70-79$ y & \$1185 [\$938-\$1374] & $\$ 958[\$ 650-\$ 1120]$ & \$1191 [\$993-\$1392] & $1240[\$ 1070-\$ 1480]$ & $1174[\$ 980-\$ 1420]$ & $1191[\$ 100-\$ 1386]$ & $1234[\$ 1080-\$ 1473]$ \\
\hline$P$ value & .08 & .05 & .07 & .07 & .07 & .08 & .07 \\
\hline \multicolumn{8}{|l|}{ Operative } \\
\hline$\geq 80 \mathrm{y}$ & $\$ 2489[\$ 1419-\$ 3012]$ & $\$ 2129[\$ 1150-\$ 2885]$ & $\$ 4848[\$ 2618-\$ 5966]$ & 4864 [\$2688-\$5837] & $2516[\$ 1344-\$ 3133]$ & $5060[\$ 2740-\$ 6720]$ & $5206[\$ 2910-\$ 6984]$ \\
\hline $70-79$ y & $\$ 2303[\$ 1207-\$ 2874]$ & $\$ 2003[\$ 1013-\$ 2746]$ & $\$ 4485[\$ 2312-\$ 5231]$ & $4500[\$ 2210-\$ 5341]$ & $2328[\$ 1225-\$ 3798]$ & $4681[\$ 2318-\$ 3995]$ & 4816 [\$2444-\$5795] \\
\hline$P$ value & .73 & .68 & .51 & .47 & .44 & .31 & .09 \\
\hline \multicolumn{8}{|l|}{ Perfusion } \\
\hline$\geq 80 \mathrm{y}$ & $\$ 2320[\$ 1235-\$ 3088]$ & - & $\$ 2412[\$ 1380-\$ 3220]$ & $2935[\$ 1675-\$ 3890]$ & $2635[\$ 1525-\$ 3870]$ & $2920[\$ 1610-\$ 3990]$ & $2897[\$ 1590-\$ 3901]$ \\
\hline $70-79$ y & $\$ 1970[\$ 1060-\$ 2390]$ & - & $\$ 2015[\$ 1150-\$ 2542]$ & $2440[\$ 1405-\$ 2800]$ & $2110[\$ 1245-\$ 2645]$ & $2380[\$ 1320-\$ 2704]$ & $2440[\$ 1395-\$ 2784]$ \\
\hline$P$ value & .08 & - & .08 & .06 & .05 & .05 & .06 \\
\hline \multicolumn{8}{|c|}{ Intensive care unit } \\
\hline$\geq 80 \mathrm{y}$ & $\$ 2620[\$ 1515-\$ 3600]$ & $\$ 2380[\$ 1375-\$ 3573]$ & $\$ 2640[\$ 1485-\$ 3678]$ & $2760[\$ 1555-\$ 3730]$ & $2600[\$ 1410-\$ 3630]$ & $3540[\$ 2190-\$ 4207]$ & $3410[\$ 2104-\$ 4140]$ \\
\hline $70-79$ y & $\$ 1934[\$ 1225]-\$ 2634$ & $\$ 1849[\$ 1056-\$ 2412]$ & $\$ 1914$ [\$1202-\$2599] & $1940[\$ 1250-\$ 2638]$ & $1874[\$ 1130-\$ 2470]$ & $2319[\$ 1660-\$ 2850]$ & $2114[\$ 1490-\$ 2780]$ \\
\hline$P$ value & .02 & .05 & .01 & .099 & .01 & $<.01$ & $<.01$ \\
\hline \multicolumn{8}{|c|}{ Postoperative room } \\
\hline$\geq 80 \mathrm{y}$ & $\$ 940[\$ 330-\$ 1102]$ & $\$ 860[\$ 280-\$ 1103]$ & $\$ 978[\$ 384-\$ 1170]$ & $1310[\$ 806-\$ 1202]$ & 835 [\$274-\$1094] & 1385 [\$850-\$9240] & $1340[\$ 840-\$ 1275]$ \\
\hline $70-79$ y & $\$ 804$ [\$225-\$955] & $\$ 550[\$ 105-\$ 741]$ & $\$ 800[\$ 220-\$ 988]$ & 1015 [\$301-\$1188] & $602[\$ 207-\$ 807]$ & $1070[\$ 312-\$ 1210]$ & 988 [\$242-\$1077] \\
\hline$P$ value & .8 & .2 & .7 & .1 & .4 & .9 & .9 \\
\hline \multicolumn{8}{|c|}{ Respiratory therapy } \\
\hline$\geq 80 \mathrm{y}$ & $\$ 1211[\$ 570-\$ 1490]$ & $\$ 1180[\$ 510-\$ 1416]$ & $\$ 1423[\$ 650-\$ 1670]$ & $1650[\$ 770-\$ 1890]$ & $1132[\$ 502-\$ 1400]$ & $1745[\$ 800-\$ 1950]$ & 1687 [\$795-\$1912] \\
\hline $70-79$ y & $\$ 550[\$ 52-\$ 200]$ & $\$ 410[\$ 40-\$ 164]$ & $\$ 545[\$ 50-\$ 195]$ & 688 [\$72-\$204] & $440[\$ 45-\$ 178]$ & $736[\$ 84-\$ 251]$ & $740[\$ 86-\$ 263]$ \\
\hline$P$ value & .006 & .007 & .008 & .009 & .006 & .01 & .02 \\
\hline \multicolumn{8}{|l|}{ Laboratory } \\
\hline$\geq 80 \mathrm{y}$ & $\$ 451$ [\$112-\$615] & $\$ 355$ [\$804-\$570] & $\$ 460[\$ 120-\$ 635]$ & $560[\$ 154-\$ 707]$ & $380[\$ 117-\$ 569]$ & $585[\$ 171-\$ 871]$ & 610 [\$194-\$965] \\
\hline $70-79$ y & $\$ 245[\$ 98-\$ 410]$ & $\$ 234[\$ 81-\$ 375]$ & $\$ 240[\$ 90-\$ 400]$ & $412[\$ 210-\$ 612]$ & $238[\$ 86-\$ 388]$ & $454[\$ 240-\$ 646]$ & $486[\$ 271-\$ 712]$ \\
\hline$P$ value & .5 & .9 & .4 & .8 & .8 & .9 & .8 \\
\hline \multicolumn{8}{|l|}{ Blood bank } \\
\hline$\geq 80 \mathrm{y}$ & $\$ 660[\$ 265-\$ 1773]$ & $\$ 594[\$ 221-\$ 1685]$ & $\$ 680$ [\$279-\$1797] & $894[\$ 334-\$ 2010]$ & $735[\$ 309-\$ 1888]$ & $1024[\$ 390-\$ 2155]$ & 975 [\$355-\$2087] \\
\hline $70-79$ y & $\$ 215[\$ 99-\$ 302]$ & $\$ 123[\$ 45-\$ 189]$ & $\$ 210[\$ 95-\$ 297]$ & $320[\$ 198-\$ 512]$ & $219[\$ 107-\$ 311]$ & $395[\$ 210-\$ 474]$ & $372[\$ 202-\$ 437]$ \\
\hline$P$ value & .07 & .06 & .06 & .04 & .05 & .03 & .03 \\
\hline \multicolumn{8}{|c|}{ Cardiology laboratory } \\
\hline$\geq 80 \mathrm{y}$ & $\$ 90[\$ 45-\$ 127]$ & $\$ 85[\$ 38-\$ 115]$ & $\$ 160[\$ 88-\$ 329]$ & 174 [\$97-\$247] & $105[\$ 71-\$ 187]$ & $237[\$ 115-\$ 325]$ & $260[\$ 129-\$ 347]$ \\
\hline $70-79$ y & $\$ 115[\$ 60-\$ 135]$ & $\$ 112[\$ 57-\$ 129]$ & $\$ 185[\$ 100-\$ 207]$ & $190[\$ 107-\$ 215]$ & $139[\$ 85-\$ 188]$ & $265[\$ 184-\$ 375]$ & $280[\$ 192-\$ 414]$ \\
\hline$P$ value & $>.9$ & $>.9$ & $>.9$ & $>.9$ & $>.9$ & $>.9$ & $>.9$ \\
\hline \multicolumn{8}{|l|}{ Radiology } \\
\hline$\geq 80 \mathrm{y}$ & $\$ 180[\$ 44-\$ 259]$ & $\$ 131[\$ 27-\$ 212]$ & $\$ 194[\$ 52-\$ 277]$ & 214 [\$64-\$295] & $170[\$ 36-\$ 244]$ & $284[\$ 98-\$ 335]$ & $201[\$ 60-\$ 286]$ \\
\hline $70-79$ y & $\$ 78$ [\$35-\$177] & $\$ 53[\$ 15-\$ 89]$ & $\$ 63[\$ 25-\$ 102]$ & $136[\$ 52-\$ 256]$ & $75[\$ 30-\$ 171]$ & $175[\$ 66-\$ 272]$ & $134[\$ 50-\$ 249]$ \\
\hline$P$ value & $>.9$ & $>.9$ & $>.9$ & $>.9$ & $>.9$ & $>.9$ & $>.9$ \\
\hline \multicolumn{8}{|l|}{ Pharmacy } \\
\hline$\geq 80 \mathrm{y}$ & $\$ 2020[\$ 1007-\$ 2486]$ & $\$ 1950[\$ 977-\$ 2379]$ & $\$ 2034[\$ 1028-\$ 2510]$ & $2100[\$ 1090-\$ 2610]$ & 2012 [\$988-\$2415] & $2090[\$ 1075-\$ 2590]$ & 2074 [\$1057-\$2533] \\
\hline $70-79$ y & $\$ 1206[\$ 434-\$ 1330]$ & $\$ 935[\$ 180-\$ 1089]$ & $\$ 1116[\$ 282-\$ 1254]$ & $1360[\$ 597-\$ 1410]$ & $1100[\$ 277-\$ 1250]$ & $1295[\$ 502-\$ 1407]$ & $1270[\$ 495-\$ 1391]$ \\
\hline$P$ value & .009 & $<.001$ & $<.001$ & .01 & $<.001$ & .01 & .009 \\
\hline \multicolumn{8}{|l|}{ Therapies } \\
\hline$\geq 80 \mathrm{y}$ & $\$ 409[\$ 106-\$ 524]$ & $\$ 320[\$ 70-\$ 455]$ & $\$ 399[\$ 101-\$ 519]$ & $443[\$ 121-\$ 585]$ & $386[\$ 97-\$ 493]$ & $515[\$ 154-\$ 698]$ & $474[\$ 137-\$ 622]$ \\
\hline $70-79$ y & $\$ 235[\$ 85-\$ 491]$ & $\$ 198[\$ 58-\$ 431]$ & $\$ 223[\$ 74-\$ 437]$ & $268[\$ 107-\$ 525]$ & $220[\$ 70-\$ 469]$ & $294[\$ 132-\$ 561]$ & $286[\$ 124-\$ 547]$ \\
\hline$P$ value & .7 & .9 & .7 & .7 & .7 & .4 & .6 \\
\hline Supplies & & & & & & & \\
\hline$\geq 80 \mathrm{y}$ & $\$ 301[\$ 44-\$ 501]$ & $\$ 298[\$ 25-\$ 473]$ & $\$ 319[\$ 50-\$ 550]$ & $324[\$ 64-\$ 559]$ & $319[\$ 56-\$ 559]$ & 336 [\$71-\$584] & 325 [\$66-\$573] \\
\hline $70-79$ y & $\$ 290[\$ 30-\$ 461]$ & $\$ 274[\$ 24-\$ 444]$ & $\$ 290[\$ 34-\$ 467]$ & $302[\$ 44-\$ 489]$ & $304[\$ 44-\$ 489]$ & $305[\$ 47-\$ 493]$ & $299[\$ 36-\$ 473]$ \\
\hline$P$ value & $>.9$ & $>.9$ & $>.9$ & $>.9$ & $>.9$ & $>.9$ & $>.9$ \\
\hline Other & & & & & & & \\
\hline$\geq 80 \mathrm{y}$ & $\$ 190[\$ 30-\$ 332]$ & $\$ 145[\$ 15-\$ 215]$ & $\$ 200[\$ 41-\$ 359]$ & $218[\$ 56-\$ 381]$ & 195 [\$34-\$349] & $224[\$ 63-\$ 386]$ & 212 [\$54-\$373] \\
\hline $70-79$ y & $\$ 178[\$ 27-\$ 326]$ & $\$ 122[\$ 20-\$ 291]$ & $\$ 188[\$ 34-\$ 353]$ & $206[\$ 50-\$ 370]$ & $179[\$ 30-\$ 334]$ & $219[\$ 61-\$ 383]$ & $203[\$ 46-\$ 361]$ \\
\hline$P$ value & $>.9$ & $>.9$ & $>.9$ & $>.9$ & $>.9$ & $>.9$ & $>.9$ \\
\hline Total costs & & & & & & & \\
\hline$\geq 80 \mathrm{y}$ & $\$ 16,759$ & $\$ 13,178$ & $\$ 19,760$ & $\$ 21,307$ & $\$ 16,902$ & $\$ 22,814$ & $\$ 22,666$ \\
\hline & {$[\$ 13,696-\$ 28,612]$} & {$[\$ 10,494-\$ 23,461]$} & {$[\$ 11,340-\$ 30,100]$} & {$[\$ 12,430-\$ 34,215]$} & {$[\$ 10,708-\$ 28,635]$} & {$[\$ 12,504-\$ 34,646]$} & {$[\$ 12,496-\$ 34,620]$} \\
\hline
\end{tabular}


TABLE 7. Continued

\begin{tabular}{|c|c|c|c|c|c|c|c|}
\hline & CABG & OРCAB & AVR & MV replacement & MV repair & Ao surgery & CABG + valve \\
\hline \multirow[t]{2}{*}{$70-79 y$} & $\$ 12,212$ & $\$ 8308$ & $\$ 14,431$ & $\$ 16,019$ & $\$ 11,917$ & $\$ 16,714$ & $\$ 16,650$ \\
\hline & [\$6120-\$1822] & {$[\$ 3220-\$ 12,615]$} & {$[\$ 6512-\$ 19,436]$} & {$[\$ 8440-\$ 23,619]$} & {$[\$ 5665-\$ 17,746]$} & [\$9762-\$25,220] & [\$8979-\$24,011] \\
\hline$P$ value & $<.001$ & $<.001$ & $<.001$ & $<.001$ & $<.001$ & $<.001$ & $<.001$ \\
\hline
\end{tabular}

Total direct costs of octogenarians and septuagenarians undergoing cardiac surgery were compared. Data are presented as median and interquartile range. Prices are in US dollars but were originally calculated in euros ( $€ 1=\$ 1.34829$ US as of May 29, 2007). Preoperative includes all costs from admission to surgery. Anesthesia includes cost of anesthetics, equipment, and disposables used by anesthesiologists. Operative includes costs of surgery, use of the operating room, surgical equipment, and disposables used by surgeons. Perfusion includes cost of cardiopulmonary bypass equipment, cardioplegia, and disposables used by the perfusionists. Intensive care unit includes cost of nursing, equipment, and room in the intensive care unit. Postoperative room includes cost of nursing, equipment, and room on the step-down unit. Respiratory therapy includes costs related to respiratory equipment. Laboratory includes cost of blood tests. Blood bank includes cost of blood typing and transfusion. Cardiology laboratory includes cost of electrocardiograms, echocardiograms, and noninvasive vascular studies. Radiology includes cost of radiologic examinations, computed tomographic scans, and magnetic resonance scans. Pharmacy includes cost of pharmacy drugs and service. Therapies includes cost of physical, occupational, and speech therapies. $C A B G$, Coronary artery bypass grafting; $O P C A B$, off-pump coronary artery bypass grafting; $A V R$, aortic valve replacement; $M V$, mitral valve; $A o$, aortic.
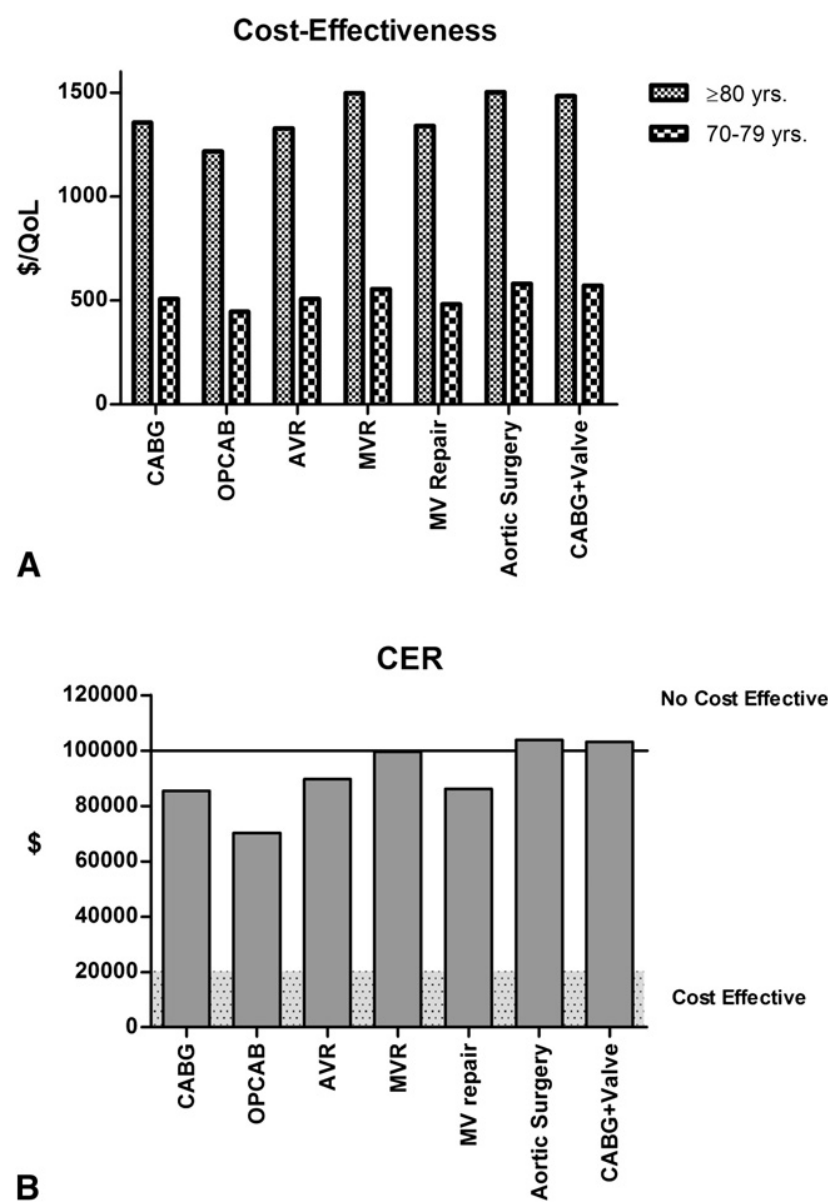

FIGURE 1. A, Cost-effectiveness by surgical procedure in octogenarians and septuagenarians undergoing cardiac surgery. Cost per quality-adjusted life year $(Q o L)$ was significantly lower in septuagenarians independent of the type of procedure. $\mathrm{B}$, Cost-effectiveness ratio (CER) by surgical procedure in octogenarians and septuagenarians undergoing cardiac surgery. The CER for octogenarians was higher than $\$ 100,000$ for aortic surgery and associated coronary artery bypass grafting and valve surgery; it was, however, above $\$ 20,000$ in all cases. $C A B G$, Coronary artery bypass grafting; $O P C A B$, off-pump coronary artery bypass grafting; $A V R$, aortic valve replacement; $M V R$, mitral valve replacement; $M V$, mitral valve. and can guide limited resource allocations and surgical indications so that patients can truly take advantage of surgery.

Undoubtedly, the increase in the cost of high-tech cardiovascular treatments and the parallel increase in the limitation of economic resources will certainly force us to consider econometric aspects in health care strategies. This will make econometric analysis an important component for any future evaluation of novel cardiovascular therapy.

\section{Limitations}

The scores of questionnaires may overestimate in some areas because of the possible bias of telephonic interview. The life years of our UC and HC groups were also estimated with a statistical model, although the Gompertz regression has been widely used to model survival time in survival analysis, especially for elderly persons. Lifetime costs of $\mathrm{HC}$ and UC groups were obtained from the general Italian population and applied to patients. For calculation of the CER, the costs of maintaining a patient in the UC group was set at 0 , which could overestimate the CER. Thus the maximum value from this formula would be $\$ 94,000$; in reality, however, it could be substantially less than that. Finally, the CER was estimated by mapping quality of life score to NYHA functional class, which is not a perfect measure of quality of life, although it has been demonstrated to correlate with quality of life.

A strength of our study was the direct measurement of costs for UC and HC groups from direct measurement of resources during a prolonged period of clinical observation.

The different categorizations of costs between the operative, HC, and UC groups might have affected the overall cost analysis. For example, home care facilities for the postoperative costs were not equivalent to home and skilled nursing facilities costs for HC and UC groups. In addition, only patients with preoperative diagnosis of severe depression were treated. Indeed, mild or subclinical depression was not assessed and treated, thus potentially representing a negative determinant of postoperative recovery, and this should be taken into consideration when interpreting our findings.

Furthermore, there was no uniformity regarding the interval after surgery at which the tests were administered, and it 
has been demonstrated that there is a reported and understandable pattern of change with time in the postoperative SF-36 score, and that results for a given individual will vary depending on how long postoperatively the test is administered. Additionally, all procedures were performed in different centers. We did, however, account for hypothetic difference in surgical conduct among Institutions participating in the study, and no significant difference was found.

Finally, it is of interest that the additive and logistic EuroSCORE values were lower (although not significantly) in the octogenarian group than in the septuagenarian group. This suggests that an inherent selection bias, which does exist in evaluating octogenarians for intervention, contributed to the clinical component of this analysis.

\section{CONCLUSIONS}

In our experience, cardiac surgery in octogenarians was shown not to be always cost-effective. Advances in cost assessment and more comprehensive patients evaluation (eg, frailty score in addition to currently available risk scores) would be essential to generate appropriate patient management. It is to be hoped that such advances would lead to more ethical and more appropriately economically oriented decision making for surgical candidates.

This study was not intended to demonstrate that surgery should generally be questioned for these patients only on the basis of service use and economic implications. It was and is intended as a call for a comprehensive evaluation of such a highly controversial issue, which because of increasing economic constraints and new therapeutic advances will be even more controversial in the future.

We gratefully acknowledge Dr Ilaria Carli, Dr Angela Salomoni, Dr Paolo Da Col, Dr Romeo Frassani, Dr Lorenzo Porreca, Dr Roberto Lumini, Dr Giorgio Morocutti, Dr Giuseppe Billè, Dr Sabina Caciolli, Mr Carlo Campani, and Mrs Viviana Giavedoni for their valuable contribution to this study. We also thank James Douglas for the English revision of the original manuscript and Dr Orlando Parise for the statistical analysis.

\section{References}

1. United Nations. World population prospects: the 2005 revision population database. Available at: http://esa.un.org/unpp. Accessed May 29, 2007.

2. Weil D. The economics of population aging. In: Rosenzweig MR, Stark O, eds. Handbook of population and family economics. New York: Elsevier; 1997. p. 967-1014.

3. Prêtre R, Turina MI. Cardiac valve surgery in the octogenarian. Heart. 2000;83: 116-21.

4. Peterson ED, Cowper PA, Jollis JG, Bebchuk JD, DeLong ER, Muhlbaier LH, et al. Outcomes of coronary artery bypass graft surgery in 24,461 patients aged 80 years or older. Circulation. 1995;92(9 Suppl):II85-91.

5. Ware JE Jr, Sherbourne CD. The MOS 36-Item Short Form Health Survey (SF36). I. Conceptual framework and item selection. Med Care. 1992;30:473-83.

6. Ware JE, Snow KK, Kosinski M, Gandek B. SF-36 health survey manual and interpretation guide. Boston: New England Medical Center; 1993.

7. Spertus JA, Winder JA, Dewhurst TA, Deyo RA, Prodzinski J, McDonell M, et al. Development and evaluation of the Seattle Angina Questionnaire: a new functional status measure for coronary artery disease. J Am Coll Cardiol. 1995;25:333-41.
8. Zung WW. A self-rating depression scale. Arch Gen Psychiatry. 1965;12:63-70.

9. Spielberger CD, Gorsuch RL, Lushene R, Vagg PR, Jacobs GA. Manual for the State-Trait Anxiety Inventory (form Y). Palo Alto (CA): Consulting Psychologists Press; 1983.

10. Rivalutazione monetaria (versione base) con indici ISTAT per le famiglie di operai e impiegati (FOI): Calcolo rivalutazione monetaria e interessi legali. RIVALUTA Web site. Available at: http://www.rivaluta.it/index7.htm. Accessed March 1, 2010.

11. Wu Y, Jin R, Gao G, Grunkemeier GL, Starr A. Cost-effectiveness of aortic valve replacement in the elderly: an introductory study. $J$ Thorac Cardiovasc Surg. 2007; 133:608-13.

12. Laupacis A, Feeny D, Detsky AS, Tugwell PX. Tentative guidelines for using clinical and economic evaluations revisited. CMAJ. 1993;148:927-9.

13. Barber G, Thompson S. Multiple regression of cost data: use of generalised linear models. J Health Serv Res Policy. 2004;9:197-204.

14. Zhao H, Bang H, Wang H, Pfeifer PE. On the equivalence of some medical cost estimators with censored data. Stat Med. 2007;26:4520-30.

15. Sedrakyan A, Vaccarino V, Paltiel AD, Elefteriades JA, Mattera JA, Roumanis SA, et al. Age does not limit quality of life improvement in cardiac valve surgery. J Am Coll Cardiol. 2003;42:1208-14.

16. Sjögren J, Thulin LI. Quality of life in the very elderly after cardiac surgery: a comparison of SF-36 between long-term survivors and an age-matched population. Gerontology. 2004;50:407-10.

17. Nissinen J, Wistbacka JO, Loponen P, Korpilahti K, Teittinen K, Virkkilä M, et al Coronary artery bypass surgery in octogenarians: long-term outcome can be better than expected. Ann Thorac Surg. 2010;89:1119-24.

18. Chaturvedi RK, Blaise M, Verdon J, Iqbal S, Ergina P, Cecere R, et al. Cardiac surgery in octogenarians: long-term survival, functional status, living arrangements, and leisure activities. Ann Thorac Surg. 2010;89:805-10.

19. Akins CW, Daggett WM, Vlahakes GJ, Hilgenberg AD, Torchiana DF, Madsen JC, et al. Cardiac operations in patients 80 years old and older. Ann Thorac Surg. 1997;64:606-14.

20. Melby SJ, Zierer A, Kaiser SP, Guthrie TJ, Keune JD, Schuessler RB, et al. Aortic valve replacement in octogenarians: risk factors for early and late mortality. Ann Thorac Surg. 2007;83:1651-7.

21. Kolh P, Kerzmann A, Lahaye L, Gerard P, Limet R. Cardiac surgery in octogenarians; peri-operative outcome and long-term results. Eur Heart J. 2001;22:1235-43.

22. Jin F, Chung F. Minimizing perioperative adverse events in the elderly. $\mathrm{Br}$ J Anaesth. 2001;87:608-24.

23. Wu Y, Grunkemeier GL, Starr A. The value of aortic valve replacement in elderly patients: an economic analysis. J Thorac Cardiovasc Surg. 2007;133:603-7.

24. Starr A, Grunkemeier GL. The cost and value of cardiothoracic procedures. J Thorac Cardiovasc Surg. 2007;133:601-2.

25. Thibault GE. Too old for what? N Engl J Med. 1993;328:946-50.

APPENDIX TABLE 1. Terminology specific to quality of life measurement

\begin{tabular}{cl}
\hline Term & \multicolumn{1}{c}{ Meaning } \\
\hline SF-36 & Medical Outcomes Short Form 36 Item Health Survey \\
PF & Physical Functioning \\
RP & Role Physical \\
BP & Bodily Pain \\
GH & General Health \\
VT & Vitality \\
SF & Social Functioning \\
RE & Role Emotional \\
MH & Mental Health \\
PCS & Physical composite score (PF + RP + BP + GH) \\
MCS & Mental composite score (MH + RE + VT + SF) \\
SAQ & The Seattle Angina Questionnaire \\
STAI & Spielberger State-Trait Anxiety Inventory \\
$X_{1}$ & STAI to measure state anxiety (how one feels \\
& at a particular moment \\
$\mathrm{X}_{2}$ & STAI to measure trait anxiety (how one usually feels) \\
SDS & Self-Rating Depression Scale of Zung \\
\hline
\end{tabular}

